\title{
The contribution of remote sensing to the assessment of drought effects in forest ecosystems
}

\author{
Michel DeshaYeS ${ }^{\mathrm{a} *}$, Dominique GuYON ${ }^{\mathrm{b}}$, Hervé JeANJEAN $^{\mathrm{c}}$, Nicolas STACH $^{\mathrm{d}}$, \\ Anne JOLLY ${ }^{\mathrm{e}}$, Olivier HAGOLLE ${ }^{\mathrm{c}}$ \\ ${ }^{a}$ ENGREF, UMR Territoires, Environnement, Télédétection et Information Spatiale, Cemagref-CIRAD-ENGREF, \\ 500 rue JF Breton, 34093 Montpellier Cedex 5, France \\ b INRA, Unité de Recherche Écologie fonctionnelle et Physique de l'Environnement, BP81, 33883 Villenave d'Ornon, France \\ ${ }^{\mathrm{c}}$ CNES, 18 avenue Edouard Belin, 31401 Toulouse Cedex 9, France \\ ${ }^{\mathrm{d}}$ Inventaire Forestier National, 32 rue Léon Bourgeois, 69500 Bron, France \\ ${ }^{e}$ Office National des Forêts, Sylvétude Lorraine, 5 rue Girardet, 54052 Nancy Cedex, France
}

(Received 28 November 2005; accepted 10 July 2006)

\begin{abstract}
Due to their synoptic and monitoring capacities, Earth observation satellites could prove useful for the assessment and evaluation of drought effects in forest ecosystems. The objectives of this article are: to briefly review the existing sources of remote sensing data and their potential to detect drought damage; to review the remote sensing applications and studies carried out during the last two decades aiming at detecting and quantifying disturbances caused by various stress factors, and especially those causing effects similar to drought; to explore the possibility to use some of the different available systems for setting up a strategy more adapted to monitoring of drought effects in forests.
\end{abstract}

drought / forest / remote sensing / satellite

Résumé - Contribution de la télédétection à l'évaluation des effets de la sécheresse sur les écosystèmes forestiers. Grâce à leurs capacités de surveillance continue, les satellites d'observation de la Terre pourraient s'avérer utiles pour l'évaluation des effets de la sécheresse sur les écosystèmes forestiers. Les objectifs de cet article sont : de passer en revue rapidement les sources actuelles de données de télédétection et leur potentiel pour la détection des dommages dus à la sécheresse; de passer en revue les études et applications de télédétection conduites pendant les deux dernières décennies et visant à détecter et quantifier les perturbations induites par différents facteurs de stress, et en particulier ceux causant des effets semblables à ceux de la sécheresse; d'explorer la possibilité d'utiliser certains des systèmes disponibles pour définir une stratégie adaptée au suivi continu des effets de la sécheresse sur les forêts.

sécheresse / forêt / télédétection / satellite

\section{INTRODUCTION}

Earth observation satellites have been used for more than 30 years for land cover mapping and forest monitoring. Most of platforms have been developed by state-owned space agencies. Commercial systems with very high resolution capabilities, mainly in the optical domain, have been developed for addressing specific markets, e.g. urban mapping, rapid mapping after natural disasters and defence needs.

In 2005, more than 60 Earth observation satellites are in operation and are providing relevant information of the planet environment, about half of them carrying dedicated sensors for land and vegetation observation at different resolution and spectral capabilities [17]. This wide range of Earth observation systems offers in principle large possibilities for forest applications, but leads at the same time to specific problems on data compatibility, calibration, geometry and continuity.

\footnotetext{
*Corresponding author: deshayes@teledetection.fr
}

No Earth observation system is fully dedicated to monitor and quantify the impact of extreme climatic situations such as the severe heat and drought of 2003 and a very limited literature on such situations is available in temperate climate, especially in Europe, specifically on drought effects.

The aims of this article are:

(1) To briefly review the existing sources and useful physical principles of remote sensing. The observable biophysical variables and processes are presented.

(2) To review the remote sensing applications and studies carried out during the last two decades aiming at detecting and quantifying disturbances caused by various stress factors. The potential use of earth observation data for detecting drought effects can be, with some limitations, derived from the similarity of the detected changes with those caused by drought.

This part gives an overview of the state of the art in the use of remote sensing for detecting and monitoring forest changes and drought effects. The first section 
outlines the capability of remote sensing to detect and track rapid vegetation structure changes such as clear cutting or storm damages. Fire-related disturbances, a very important and specific issue in forest management, are not considered here. The following sections deal with monitoring of changes resulting from continuous and progressive mechanisms, such as forest decline or phenological disturbance or productivity reduction, with a focus on vegetation anomalies due to drought and water stress. The last section addresses the future prospects given by the process-based models of carbon and water fluxes. The main findings of the few papers dealing the severe 2003 drought are presented.

(3) To explore the possibility to use some of the different available systems for setting up a strategy more adapted to monitoring of drought effects in forests.

\section{BRIEF REVIEW OF THE EXISTING SOURCES OF USEFUL DATA AND OF THE OBSERVABLE BIOPHYSICAL VARIABLES}

The multiplication of space technologies, e.g. optical to radar sensors, active and passive systems, is opening new possibilities for deriving some key biogeophysical parameters of forest ecosystems. However, various factors are still limiting research advances, e.g. the difficulty in modelling the signature of tree canopy captured by space sensors, the complexity of forest ecosystem functioning, and the still limited capabilities of space observation before reaching an operational dimension. Ground measurements remain mandatory for bringing a comprehensive and consistent picture of forest conditions.

\subsection{Remote sensing in the optical domain}

In the short wavelengths ranging from visible to infrared $(400-2500 \mathrm{~nm})$ the sensors measure the solar radiation reflected by the Earth surface The ratio between reflected energy on incident energy is called reflectance: expressed as a percentage, it depends on wavelength and on the way the radiation interacts with objects. The processes of reflection, absorption, transmission differ strongly according to the wavelength range: visible between 400 and $700 \mathrm{~nm}$ (VIS), near infra red between 700 and $1100 \mathrm{~nm}$ (NIR) and short wave infrared between 1100 and $2500 \mathrm{~nm}$ (SWIR).

In far infrared or thermal infrared (TIR) ranging from 8 to $14 \mu \mathrm{m}$ the sensors measure the radiation emitted by the Earth surface. The surface temperature retrieved from thermal infrared measurements is determined by energy budget at the surface.

\subsubsection{Spatial resolution of the sensor}

It can vary from tens of centimetres (aerial photographs) to several kilometres (meteorological satellites) (Fig. 1). The spectral response or reflectance of the observed unit on the ground is an aggregate of spectral responses from different objects, e.g. single trees or tree canopies, soil, other vegetation layers, all both in sunlight and in shadow. The larger the size of the "pixel", the more there are different objects included. In medium scale (1:30000) to large scale (1:5000) photographs, and in very high resolution satellites images (below meter resolution), a tree is covered by several pixels, enabling detailed canopy structure and texture to be extracted ([21] for instance). In high resolution satellite images (10 to $100 \mathrm{~m}$ ), a pixel covers several trees: this resolution is particularly adapted for monitoring forests at stand level. Medium and low resolution satellite data are well suited for regional forest surveys and monitoring. Pixels between 100 and $500 \mathrm{~m}$ cover one to several hectares, but still contain relevant information on forest canopy properties. This is still valid for lower resolution, e.g. $1 \mathrm{~km}$, imagery in widely afforested regions.

\subsubsection{Spectral bands and spectral resolution}

Space-borne optical imagers can usually operate in the panchromatic mode (large spectral band width at high spatial resolution), and in the multispectral mode (several spectral bands with narrower width at lower spatial resolution). The spectral band is characterised by the wavelength and the band width. The finer the spatial resolution, the less is the energy received at sensor level. For technical reasons, it is difficult to develop very sensitive sensors with narrow spectral bands. This is the reason why the spatially finest sensors (below meter) operate in the visible domain with a large (about $400 \mathrm{~nm}$ ) panchromatic mode: this source of data is particularly adapted for detecting structural patterns or features of the forest stands: limits of different forest types, logging roads, clear cutting, canopy texture, etc. The multispectral mode is more adapted for characterising vegetation: canopy density, photosynthetic activity, water stress, fire activity, etc. The number of spectral bands of a multispectral sensor ranges from just a few (i.e. SPOT satellites) to more than 200 bands on hyperspectral spectrometers. Spectral bands in the visible (blue to red wavelengths), near infrared (NIR) and short wave infrared (SWIR) are particularly interesting for vegetation monitoring. The bandwidth of satellite sensors is generally around $100 \mathrm{~nm}$ but some low or medium resolution sensors such as MODIS (500 and $1000 \mathrm{~m}$ ) or MERIS $(350 \mathrm{~m})$ present narrower bands (10 to $30 \mathrm{~nm}$ ) more adapted to the retrieval of certain biophysical features. The thermal infrared domain (TIR) is used for studying water fluxes between vegetation and atmosphere, for estimating the evapotranspiration of vegetation canopies and for detecting water stress. Several TIR spectral bands are necessary for separating temperature and emissivity and for correcting atmospheric effects.

All disturbing effects of the signal, e.g. atmospheric influence or directional effects, need to be properly corrected. Imaging sensors with high signal to noise ratio are now considered as a prerequisite for better addressing vegetation processes. For instance this point is crucial for the reflectance of forest canopies in the visible wavelength which is usually low especially in the case of coniferous trees. 


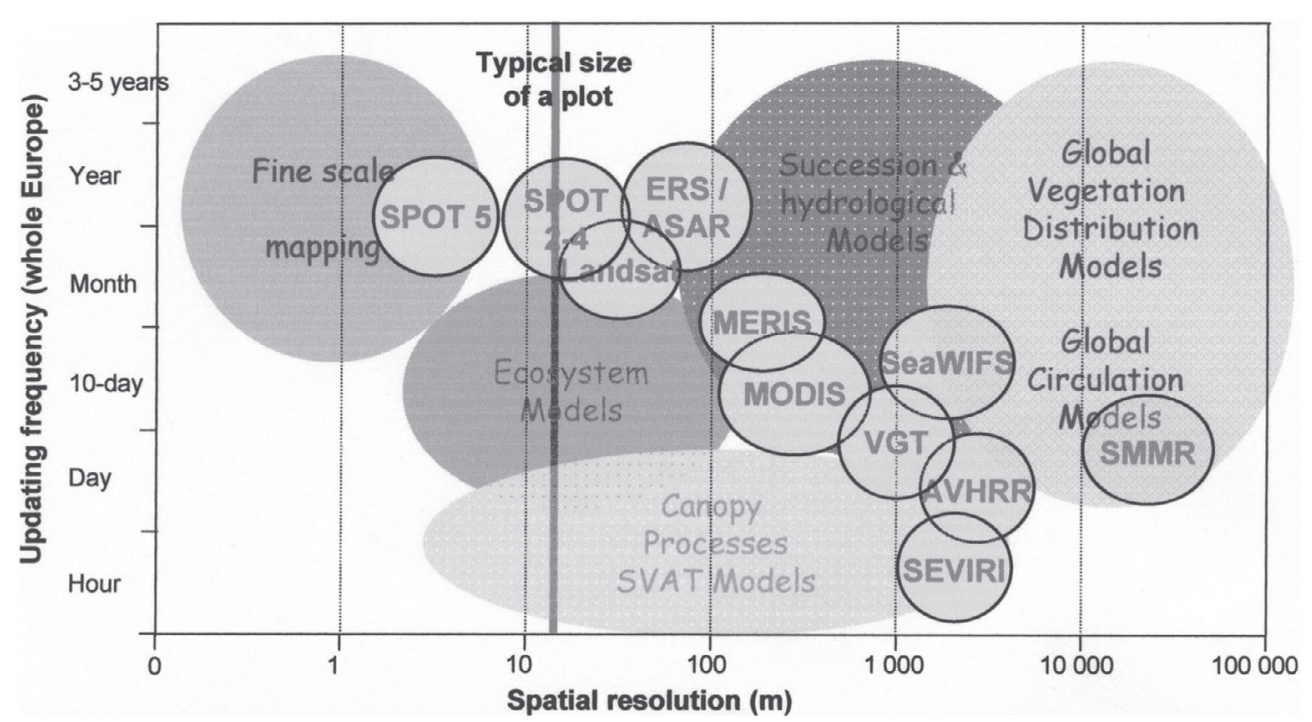

Figure 1. Spatial resolution and updating frequency for complete coverage of whole Europe associated with presently operating remote sensing satellites $($ SVAT $=$ Soil-Vegetation-Atmosphere Transfer, VGT $=$ Vegetation $)$.

\subsubsection{Temporal resolution}

The revisiting frequency over the same area depends on satellite and sensor specifications, i.e. sensor swath and system manoeuvring capability. The temporal resolution ranges from 15 min for geostationary satellites to more than 20 days for some low orbit satellites (Fig. 1). The along or across track viewing facility increases the agility of the satellites, giving more opportunity to capture images of a given site, and thus improving the temporal resolution. Appropriate algorithms have been developed for properly correcting long time series and for deriving the temporal reflectance with cloud screening, atmospheric correction, geometric correction and radiometric calibration accounting for directional effects [45] .

For instance, the VEGETATION instrument on SPOT4 and 5 satellites, operating at $1.1 \mathrm{~km}$ resolution with $2000 \mathrm{~km}$ swath, is covering the entire continents almost every day and is used for studying vegetation processes at small scale, with its evolution and variation between seasons or years. On the other hand, the SPOT 5 HRG sensor with its moving mirrors can take a $60 \times 60 \mathrm{~km}$ image at $2.5 \mathrm{~m}$ resolution only every 6 days over a fixed site: in this case, the images will be taken under different viewing angles. The revisit capability is only 26 days for an image taken under the same viewing conditions. The frequency of observation with the HRVIR sensor on board of SPOT4 is similar, but the spatial resolution of HRVIR is lower (10 or $20 \mathrm{~m})$.

\subsubsection{Physical processes and observable biophysical variables}

The reflectance of a forest canopy is related to the wavelength and depends on several biophysical parameters such as crown closure, Leaf Area Index (LAI), chlorophyll and water content of the leaves, architecture of the branches and leaves, structure and composition of the under-storey layers (bush, forest litter, bare ground, etc.) and sub-surface properties of soil. The topography, which is too often neglected, also has an indirect effect, as do the measurement conditions (incidence angle of the sun rays and of the space sensor, fractions of direct and diffuse radiation).

At leaf level, it is well known that radiation is subject to a strong absorption due to chlorophyll pigments in the VIS wavelengths, to a strong diffusion controlled by the internal structure of the leaf in the NIR and by a relatively strong absorption by water in the SWIR. As a consequence forest parameters derived from these driving forces such as LAI and equivalent water thickness do play a role at stand level, together with other ones such as tree cover fraction and to some extent soil moisture.

Radiation absorption in the SWIR is less intense than in the visible range for typical green leaves and therefore the reflectance of tree canopies in the SWIR is greater than in the visible range and lower than in the NIR. Similarly the SWIR band is much more sensitive to variations in LAI than the visible range.

The forest stand structure determines the fractions of illuminated and shadowed elements composing the vegetation layers (crown, under-storey and soil). Shadowed surfaces receive a diffused radiation which is much weaker in SWIR than in NIR. This results in darker shadows in the SWIR than in the NIR. Associated to its low sensitivity to atmospheric effects and its high signal-to-noise ratio, it makes therefore SWIR very sensitive to variations in the tree canopy structure, e.g. LAI or cover fraction [13,42]. Thus this spectral band may be very useful for detecting structure changes such as clear cuts and thinnings $[52,54]$. Forest attributes, such as standing volume, age and tree height, are often correlated one to another to some extent. They can be sometimes retrieved from remote sensing data by inverting reflectance models related to 
biophysical parameters or by applying empirical relationships, since they are related to density of vegetation elements (i.e. green LAI) and their spatial distribution.

Water stress can affect the SWIR signal directly since there is less water in the leaves. It can change also indirectly the vegetation response in all the wavelengths by inducing anatomical changes in the leaves, or altering pigments or reducing LAI $[9,85,106]$.

The NDVI (Normalised Difference Vegetation Index $\left.\frac{\rho_{N I R}-\rho_{R E D}}{\rho_{N I R}+\rho_{R E D}},[86]\right)$ and various other vegetation indices combining reflectance in red wavelenghts (RED) and NIR [5] are classically used for quantifying such biophysical variables as LAI, biomass or absorbed photosynthetically active radiation or net primary production ([98], among others). The ratio $\frac{\rho_{N I R}-\rho_{S W I R}}{\rho_{N I R}+\rho_{S W I R}}[60]$ is another useful vegetation index since it tends to saturate less quickly with the LAI or the cover fraction than NDVI. SWIR-based vegetation indices are also more sensitive to the vegetation moisture, but generally they only detect important variations (around 50\%) in vegetation moisture, well above ordinary variations, around $20 \%$ [51]. The results could be improved with the use of narrow spectral bands (10 or $20 \mathrm{~nm}$ instead of $100 \mathrm{~nm}$ ) as available from aerial hyperspectral sensors such as AVIRIS [33] or certain recent lower spatial resolution sensors such as MODIS [23].

The use of thermal infrared data which allow the retrieval of surface temperature is an efficient way for estimating surface fluxes. The relationship between temperature and sensible heat flux gives access to latent heat flux (LE), with the knowledge of the energy balance. LE is a component of the energy budget. It is controlled by availability of soil water, which results from the water balance. This approach has been successfully used by numerous authors to quantify evaporation at regional scale from the thermal infrared spectral bands of satellite sensors such as AVHRR/NOAA or METEOSAT. The instantaneous brightness temperature measured by satellite can be combined with land surface processes models or a simplified semi-empirical relationship with the daily evapotranspiration in order to estimate the daily value of the actual evapotranspiration. The estimates which have an accuracy on the order of $\pm 1.5 \mathrm{~mm}$ are particularly valuable for describing spatial variations of evaporation difficult to obtain from other techniques [89]. The accuracy in the retrieval of the surface temperature is partly depending on the error on surface emissivity and the atmospheric correction procedures. The directional effects on the measured brightness temperature is another source of error. The satellite systems well suited for the estimation of fluxes at regional scale have a large field of view; for instance the field of AVHRR/NOAA leads to nadir view angles ranging from 0 to $55^{\circ}$. Lagouarde et al. [63] showed over a maritime pine forest that the hot spot effect due to the sensorsun geometry is important and the variations between vertical and oblique measurements temperatures may reach about $4{ }^{\circ} \mathrm{K}$ for the moderate to large water stress conditions studied. The reader will find a basic review on the use of thermal infrared data for estimating heat fluxes in [89].

Fine resolution data provided by aerial photography and space-borne sensors have proved to be adapted for character- ising forest condition, from tree level to stand level: forest/non forest discrimination, mapping of main species types (coniferous, broadleaves), tree density to canopy height.

As regards the use of medium and low resolution satellite data, the most significant advances in the past years have been achieved with the use of the high temporal frequency capability for analysing and modelling forest ecosystem functioning, with the retrieval of biophysical parameters such as vegetation phenology and cycle duration, LAI, fraction of cover, fraction of Absorbed Photosynthetically Active Radiation (fAPAR), albedo, soil moisture, energy fluxes, water and carbon fluxes, fuel moisture content... The thermal infrared range (TIR) is useful for land surface temperature LST and energy fluxes retrieval, leading to water balance and water stress detection. Numerous projects are currently being carried out by the scientific community for developing and validating the estimation of these parameters.

Abrupt and drastic structure changes, caused by syIvicultural practices (clearcuts, thinnings, etc.) or by natural hazards (fire, storm...) can be detected and quantified by space sensors, depending on their spatial resolution and the spatial extent of the phenomenon to be observed. More subtle and progressive changes, mostly caused by natural factors, e.g. pest and disease or drought, are often characterised by a modification of water and chlorophyll content (pigments composition...), by a slow evolution of the morphology of leaves and the structure of tree crowns, and ultimately by defoliation and tree decline. Such changes are more difficult to detect, monitor and quantify.

As a conclusion, tracking slow vegetation changes, e.g. water stress due to severe drought and heat, will require both medium or low resolution satellite images for monitoring vegetation and forest canopy evolution on a daily basis and higher resolution images at lower frequency for better characterising the properties at tree and stand levels, as well as for disaggregating lower resolution pixels.

\subsection{Remote sensing in the microwave domain}

The spectral domain of microwaves ranges from about $1 \mathrm{~cm}$ to $1 \mathrm{~m}$. There are two kinds of observation. The passive systems observe the radiation naturally emitted by the surface. The active systems or Radar emit a radiation and record its backscattering by the earth surface.

\subsubsection{Radar}

Radar (RAdio Detection And Ranging) technology is a technology that has been developed and used for many years by the military sector and has first become available to scientists in 1978 (SEASAT satellite). Despite dramatic advances towards operational applications in forestry, it still needs significant efforts from the scientific community before reaching a level where data can be used on a routine basis. However, this source of information potentially represents a very interesting alternative to optical sensors, especially in regions 
where cloud cover is hampering the acquisition of good quality scenes. Radar information is also in many cases a complementary source of information as radar sensor "sees" the object in a very different way than optical sensors.

The basic principle of a radar system is to transmit short and high energy pulses and to record the quantity and time delay of the energy backscattered. Usually, the same antenna is used for transmission and reception. The radar electromagnetic radiation is characterised by its direction of propagation, amplitude, phase, wavelength and polarisation either vertical (V) or horizontal (H). Real Aperture Radar (RAR) and Synthetic Aperture Radar (SAR) are the two types of imaging radar. For space-borne radar, SAR is the most frequently used. The sequence of pulses is processed on SAR systems to synthesise an aperture that is much longer than the actual antenna. The nominal azimuth resolution for a SAR is half of the real antenna size. Generally, the resolution achieved is of the order of 1-2 $\mathrm{m}$ for airborne radar, and 10-100 $\mathrm{m}$ for space-borne radar systems. New systems reaching $1 \mathrm{~m}$ resolution are expected to be launched in a short term.

The radar backscattering coefficient $\sigma^{0}$ provides information about earth surface and is depending on several key features: (i) radar system parameters, i.e. frequency, polarisation and incidence angle of the electromagnetic radiation, and (ii) surface parameters, i.e. geometric properties of the object, surface roughness and dielectric constant. The radar observation parameters will determine the penetration depth of the microwave into the ground targets, the relative surface roughness and possibly the orientation of small scattering elements of the target.

Different wavelengths, designated by letters, are used in microwave remote sensing. With longer wavelengths, penetration of the radiation tends to increase. For instance, over a forest canopy, radiation in $\mathrm{X}$ band (with wavelength around $3 \mathrm{~cm}$ ) will be limited to a few centimetres, while in $\mathrm{C}$ band (with wavelength around $6 \mathrm{~cm}$ ), the waves will go deeper into the crowns. In L and P band (respectively around 25 and $60 \mathrm{~cm}$ ), the penetration is going further down to trunks and eventually to the soil. Thus, the information carried by radar radiation is closely related to vegetation biomass, depending on the interaction of the microwaves with different layers of the vegetation canopy. The penetration is also strongly affected by surface roughness and moisture. Increasing moisture results in increasing radar reflectivity.

The European ERS-2 satellite, operating in C band and VV polarisation at 30-m resolution, followed by ENVISAT-ASAR with similar characteristics, and the Canadian Radarsat-1 satellite, operating in the same band with $\mathrm{HH}$ polarisation at 10 to $100 \mathrm{~m}$, are the existing space systems able to procure complementary information on forest conditions. Amplitude C-band radar data are found to be of limited use for mapping forest types and deforestation [81]. This is due to the rather quick saturation of the signal with forest biomass in this frequency, thus preventing the separation of successive stages of vegetation regrowth.

With the imaging radars operating in longer wavelengths (L-band, possibly P-band in the future), it is possible to push back the saturation limit [105]. In addition, the HV polarisa- tion is found to be more sensitive to biomass than VV. In another study, three broad classes of regenerating forest biomass density were positively distinguished [69]. In their review, Kasischke et al. [58] recommend to use multiband and multipolarisation SAR data for mapping vegetation and for estimating forest biomass with better precision than with single frequency and polarisation systems.

As regards monitoring damages to forests, radar data have been assessed for detecting and mapping burnt areas. These studies have been using C-band data (ERS, Radarsat) and have been carried out in boreal regions, in North America [8, 32, 47, 57] and in Siberia [77], in the Mediterranean region [34, $35]$, and in tropical regions $[62,90]$. Burnt scar mapping has been found possible, which has generally been explained by changes in soil humidity [47].

As regards soil moisture monitoring, radar may give some information for bare soil or for sparse vegetation. In the case of dense vegetation like European forests the contribution of the soil in X-and C-band signals is generally too weak because of the strong attenuation by the vegetation layer.

In conclusion, the potential of radar for monitoring the effects of drought are yet to be fully explored. SAR in X or C band could be sensitive to the modification of low leaf biomass at stand level, but the major drawback is the limitation of ground resolution and the lack of continuous time series.

\subsubsection{Passive microwaves}

Passive microwave sensors measure the natural microwave emission of the land surface. The brightness temperature measured by the radiometer depends on the emissivity and the surface temperature. The variations of emissivity provide information on surface soil moisture and vegetation water content, as with TIR imagery. Contrary to TIR sensors passive radar sensors are insensitive to cloud cover and can thus provide a complementary information. Their spatial resolution is very low, $10 \mathrm{~km}$ to $100 \mathrm{~km}$, but their temporal resolution high, 1 to 3 days. Various studies have shown the ability of the passive microwave sensors to monitor surface soil moisture with a high temporal frequency. The different soil moisture retrieval approaches depend on the way vegetation and temperature effects on microwave signal are accounted for [104]. The attenuation of microwave emission by vegetation is related to its water content; it may be estimated from green LAI derived from visible and infrared remote sensing data.

\subsection{Complementary nature of ground-based measurements}

In situ measurements can be combined with airborne and space borne data for different reasons: (i) calibration and validation of methods or models, (ii) temporal or spatial interpolation of ground observation network; (iii) assimilation into models or simulation tools on ecosystems functioning, forest growth simulation and prediction of forest production. 
Two permanent (long-term) ground-based observation networks have been established for monitoring the condition of the whole European forests with the so-called Level 1 and 2 of the European-ICP Forests /EU system. The national systems for inventorying forest resources from National Forest Inventories agencies are also useful when permanent networks of sampling plots are used. Various long-term forest experiments are achieved with few sites. We can mention particularly the continuous measurements of fluxes of $\mathrm{CO}_{2}$, water, radiation... (i.e. Eddy Covariance Tower Network) and the intensive monitoring of phenologic stages (phenologic gardens for instance), LAI (litter fall measurement in some ICPLevel2 plots for instance), and growth of trees (i.e. dendrometric data). These data obtained at local scale are valuable for calibrating the geospatialisation of processes derived from remote sensing data. The availability on the region under monitoring of other information such as, for instance, meteorological measurements from weather stations networks or maps of hydrological soil properties is also useful. Mårell et al. [70] give a classification of these facilities and a rough estimate of the facilities available in the different European countries.

\section{APPLICATIONS FOR MONITORING FOREST CHANGES AND DROUGHT EFFECTS}

Disturbances on forest condition can be caused by numerous factors driven by human-induced or natural mechanisms. Several factors are most often interacting with each other, rendering the diagnostic even more complex. Remote sensing tools have been widely tested for tracking forest changes, taking benefit of the revisit frequency over a given area combined with a relatively large coverage capability.

Rapid changes, e.g. clear cutting, fire scars or storm damage..., can usually be detected and quantified with a satisfactory accuracy as they occur in a limited period of time on the same stand - several h to few days - and as observations from space can provide timely information right after the disturbance. But the detection capability depends on the intensity and extent of disturbance, and the availability of recent archive for cross comparison. The degree of persistence is also a key factor in the feasibility of remote sensing for detecting rapid changes.

Changes resulting from continuous and progressive mechanisms, such as forest decline or phenological alteration or productivity reduction, are more difficult to detect with spacederived observations. The relatively low intensity of disturbance requires long term series of observations before depicting any sign of disturbance.

\subsection{Detection of sudden changes in forest structure}

The development of remote sensing methods dedicated to detection of sudden and strong forest structure changes, e.g. clear cut and storm damage assessment, has been rapidly progressing during the last ten years with the increasing need to define indicators of sustainable management and to implement certification procedures. In addition, the preparation of the European programme on Global Monitoring for Environment and Security is expected to lead to the implementation of operational services such as the reporting on forest areas and changes in the framework of the Kyoto protocol.

The resolution of optical data at 10 to $30 \mathrm{~m}$ is too broad for mapping forest types according to most European National Forest Inventory schemes. These data have however proved to be effective for updating and enriching existing maps. The operational use of such data for an annual mapping of the clear felling of Pinus pinaster stands over the 1 million ha Landes forest in Aquitaine Region has been clearly demonstrated $[54,55,93]$. Thus since 1999 , IFN the French national forest inventory agency has been carrying out the assessment of annual clear cuts from 1990 onwards over the whole Landes forest (Fig. 2), using Landsat 5 TM and Landsat 7 ETM satellite data [93]. The method is based on a change detection procedure, followed by a visual inspection of low probability possible clear cuts $[30,54]$. The rate of clear cutting by age class is afterwards determined by combining the annual clear cut map with ground inventory plots.

In April 2000, IFN used the clear cut mapping method for assessing the damages of the 1999 storm over the northern part of the Landes massif [92]. A map was produced with 5 damage classes $(0-20 \%, 20-40 \%, 40-60 \%, 60-80 \%$ and $80-$ $100 \%$ ). In 2002, satellite remote sensing methods have been tested for mapping storm damage in other French regions and under different local conditions $[94,95]$. The study has shown that change detection protocols together with segmentation techniques can be applied to satellite images acquired during late spring and summer, leading to satisfactory results. The method has been applied to Vosges forests in flat and hilly areas (Fig. 3) [95].

\subsection{Monitoring forest health and decline}

This section gives an overview of the remote sensing tools developed during the last 10 to 20 years for monitoring forest health and decline. Damage to forest health may occur as a result from short term biogenic aggressions as well as long term impact of drought and other abiotic factors.

Typical forest decline symptoms are foliage chlorosis (degradation of chlorophyll pigments), foliage loss, degradation of tree crown structure, and tree mortality. Forest decline and dieback can be caused by various factors, such as pests and diseases, air pollution, or even long term effect of climatic extremes situations (drought, frost...) etc. The causes are often multiple and difficult to identify and separate from each other.

Aerial photographs at large scale (1:5000 to 1:10000, spatial resolution $<30 \mathrm{~cm}$ ), with panchromatic, colour and better with infrared colour films, have been commonly used over the past two decades for assessing individual tree crowns and mapping damage areas. As typical examples of earlier studies triggered by drought effects one can mention the assessment of the oak decline in the Tronçais (central France) forest which 


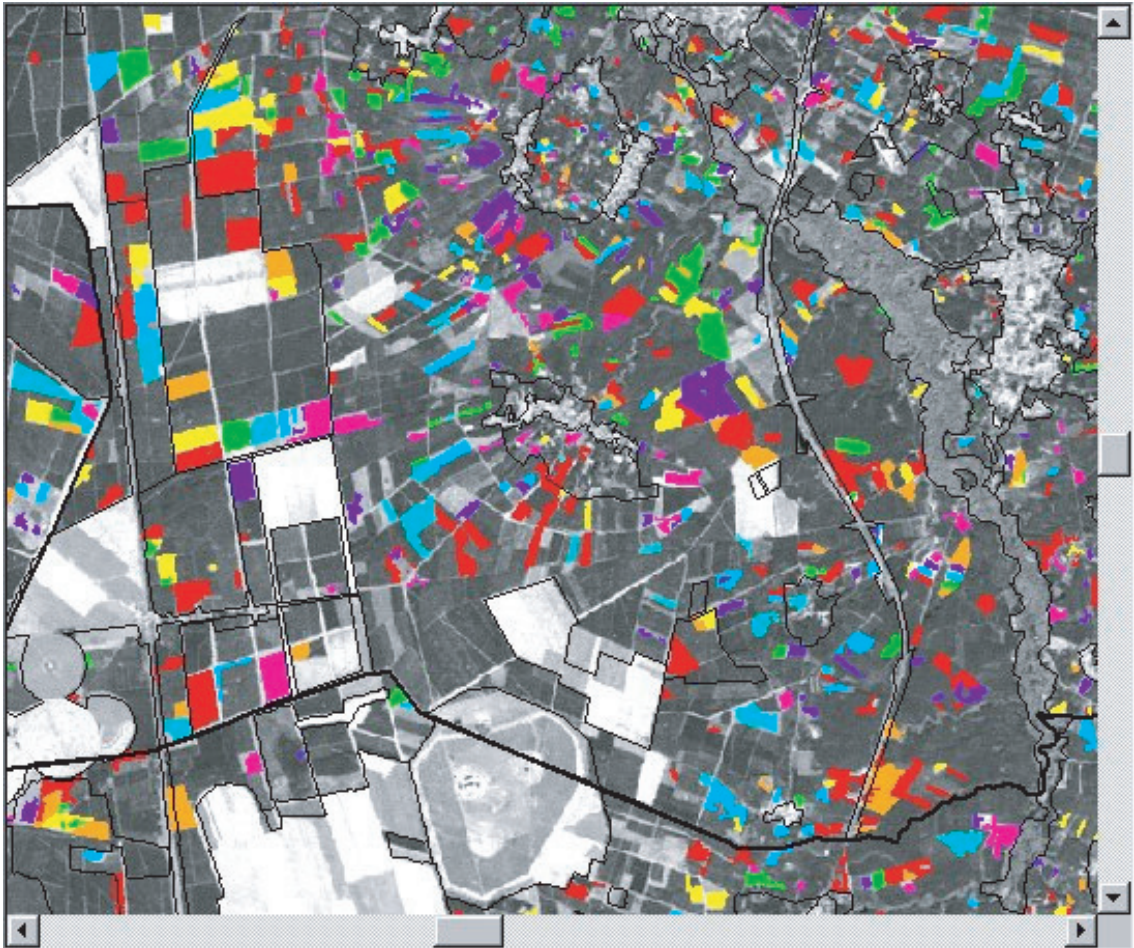

Between $11 / 07 / 90$ and 09/04/91

Between 09/04/91 and 20/09/92

Between 20/09/92 and 01/06/93

Between 01/06/93 and 22/07/94

Between 22/07/94 and 07/06/95

Between 07/06/95 and 29/09/96

Between 29/06/96 and 18/10/97

Between 18/10/97 and 18/10/99

Figure 2. Annual clear cut mapping in Landes forest with Landsat TM (period 1990-1999).

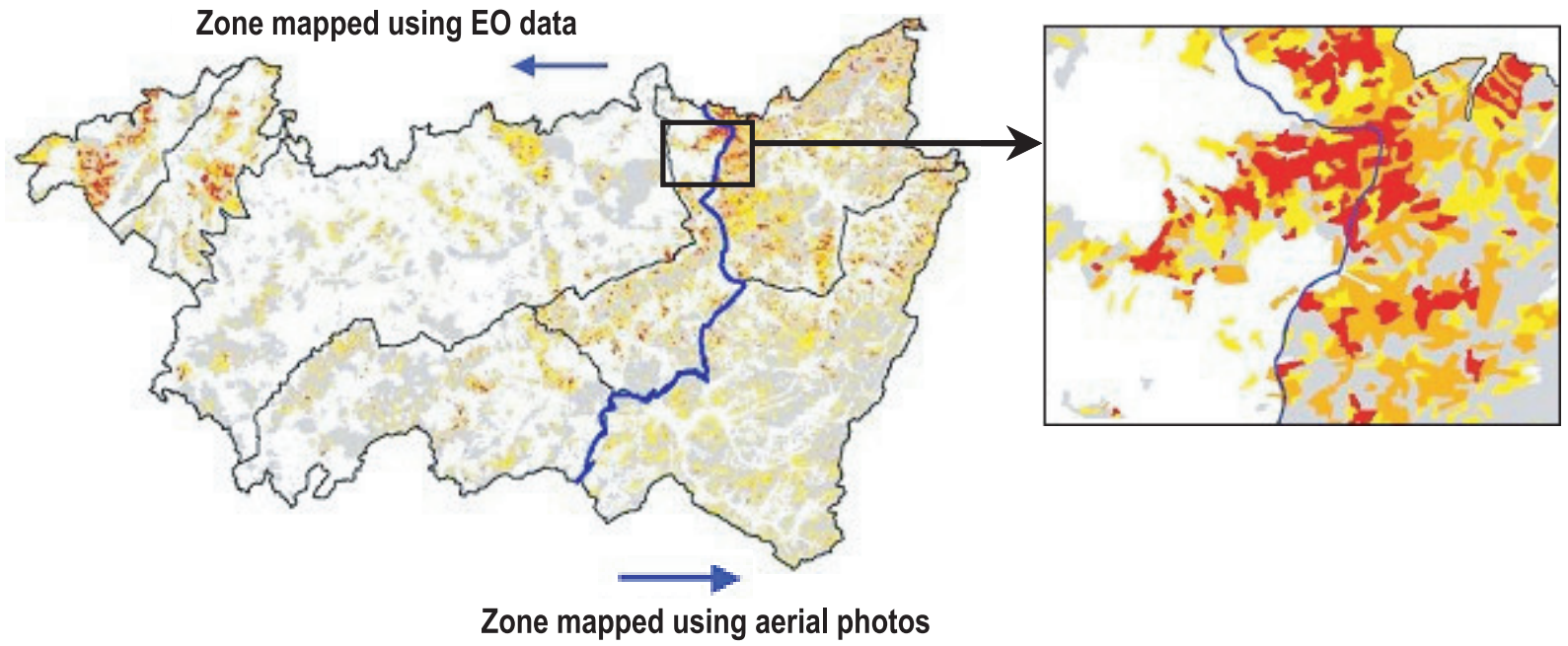

Figure 3. Damage map of 1999 storm using satellite and aerial data over Vosges department ( $\left.5875 \mathrm{~km}^{2}\right)$, France. Left: global view; Right: local zoom.

occurred after the exceptional 1976 drought [82], as was as well as Pyrenean piedmont [29]. In the early 1990s, the oaks of the Harth forest (Alsace, north-eastern France) underwent a serious decline following the 1989-1991 dry period, and the forest health condition was mapped [78].

The main symptoms are generally progressive crown deterioration occurring one or several year(s) after the drought and not short-term drought symptoms such as foliage browning, withering and early fall. More generally, typical drought effects are quite rare in temperate forests - the symptoms ob- served during 2003 represent an extreme case - and many of the potentially drought triggered symptoms are assessed as damage of unknown origin.

So far, the most extensive use of aerial photographs in Europe took place during the 1980s, when several campaigns were launched in order to assess "forest decline", supposedly due to air pollution [1,31, 49, 83, 84] among others). The main investigations have been carried out in Germany, e.g. Black Forest, in Belgium and in France, e.g. Vosges. The damage assessment and their mapping were mostly based on 
a multi-stage sampling scheme with the use of aerial photographs for stratification. Geostatistics techniques have been applied for optimising the sampling design and assessing the spatial errors on the decline intensity estimates [40]. Standardisation and coordination initiatives have been attempted at regional level by the European Commission [1,48]. Ground monitoring networks such as the EU/ICP Forests $16 \times 16 \mathrm{~km}$ Level 1 Network offer a complementary and necessary source of information: the information can be spatially extrapolated with a high sampling design using large scale aerial photographs. As a consequence, the spatial precision of inventories is improved, and spatial processes of decline, e.g. spatial epidemiology and relation with environment variables, are better understood.

The large scale photography has proved its efficiency for monitoring forest damages (Fig. 4). The identification of the species and the estimation of the degradation intensity of crown structure of each inventoried tree are accurate when they are based on the use of three-dimensional information obtained from a visual interpretation using a stereoscope. Photogrammetric techniques were hardly used for locating the trees or estimating their size. Now the trend is towards replacing the film with a digital sensor and replacing the tedious conventional visual interpretation with automated image processing. The present development of automated methods for retrieving the tree or canopy structure from airborne or spaceborne digital images with spatial resolution less than the tree size could be profitable (see for instance [46]).

Aerial photographs at smaller scale (1/10000 to $1 / 30000)$ and satellite data at metric to decametric resolution are well suited for forest monitoring at stand level. Numerous studies on air pollution effects and pests and diseases impacts on forest condition are reported in the literature since $1980[2,7,44$, $50,64,65,73,80,87,88,91,96,97,107]$, among others) and show that "severe" damage (affecting a "sufficient" number of trees) can be easily detected, while scattered tree decline is difficult to see with the limited resolution of space remotely sensed data $[6,24]$, and without ground assessment. Finally, the feasibility of depicting forest decline is closely depending on the topography of the study area, on the structure of forest stands, on the date and frequency of data acquisition and on the spatial resolution of the remotely sensed data.

Important forest defoliation can be easily detected by satellite remote sensing. For example, defoliation by gypsy moth (Lymantria dispar) can be mapped and monitored from satellite imagery $[19,56]$. Two types of techniques can be used to map defoliated areas or levels of defoliation: firstly by using only one image taken during the defoliation, and photointerpreting or classifying it; secondly by using two images, one after and one before the attack, and by comparing the two images with rating or differencing techniques. Using colour composite transparencies, Ciesla et al. [19] have found some limitations in the assessment of defoliation intensity, inducing commission errors, and Joria and Ahearn [56] errors due to the presence of non-forest areas or forest margins on the scenes. SPOT/HRV colour composites were found to take considerably less time ( $5 \%$ only) than the interpretation of aerial photos, yet providing similar results [19]. A Landsat TM classifi-

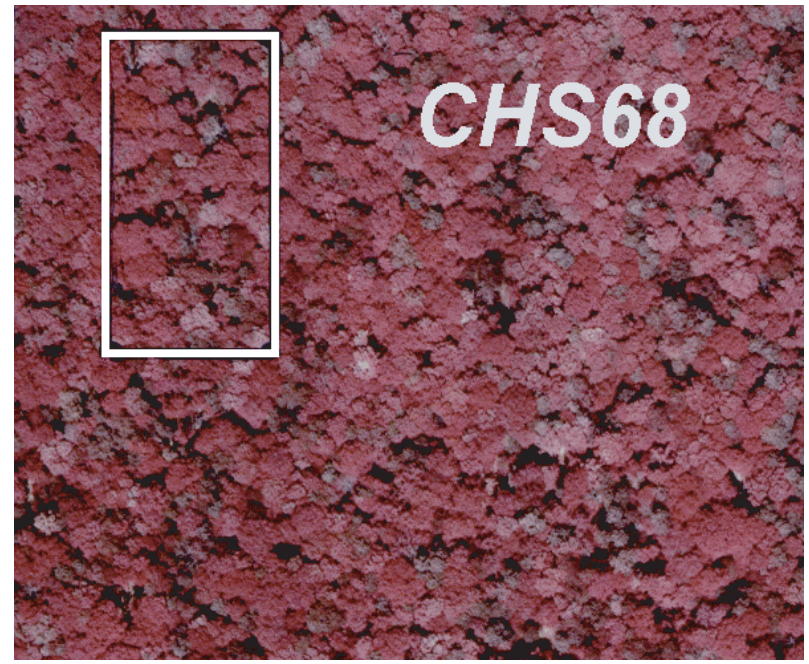

Figure 4. Detailed view of an infrared colour aerial photograph at 1:5000 taken over Harth forest, France (August 1994, spatial resolution about $15 \mathrm{~cm}$ ). Rectangle indicates the CHS68 plot of the Level 2 European ground-based observation network (French RENECOFOR network). Oaks are declining and the lime tree understory is at an early senescence stage (Guyon et al. 1997 [41]).

cation differentiating two levels of defoliation, moderate and severe, and no defoliation was found to have a $82 \%$ agreement with aerial photography and supplementary ground data.

More recently, massive defoliations caused by gypsy moth were observed on the oak in the forest of Haguenau in northern Alsace during 1993 and 1994. These defoliations have been considered as a consequence of the 1989-1991 dry period. The defoliation intensity was assessed in the field and recorded within a GIS database by the local forest managers (ONF, French National Forest Agency). Landsat TM and SPOT HRV data taken before and after defoliation were used in order to investigate the capability of satellite data in detecting defoliations in this area. The change detection method was a 5-step approach [25,30]: (i) radiometric and geometric preprocessing, (ii) relative radiometric normalisation of the images, (iii) computation of the difference image, (iv) analysis of radiometric evolution, and (v) threshold classification and mapping of gypsy moth damage. Results indicate that in the defoliated areas the reflectance in the NIR range decreases, while it increases in the VIS domain and even more in the SWIR domain (Fig. 5). An extension of the damage between 1993 and 1994 was noticed, and the comparison with in situ observations has shown that the satellite-based estimates agree with ground truth (Fig. 6).

Following these encouraging results, the same method has been applied over two French "départements" of western France (Deux-Sèvres and Vienne, total area $12990 \mathrm{~km}^{2}$ ) for mapping the gypsy moth attack that took place during years 1992 and 1993 [24]. Defoliation maps have been produced. However, mapping mortality was not possible since the dead trees were isolated and scattered. 

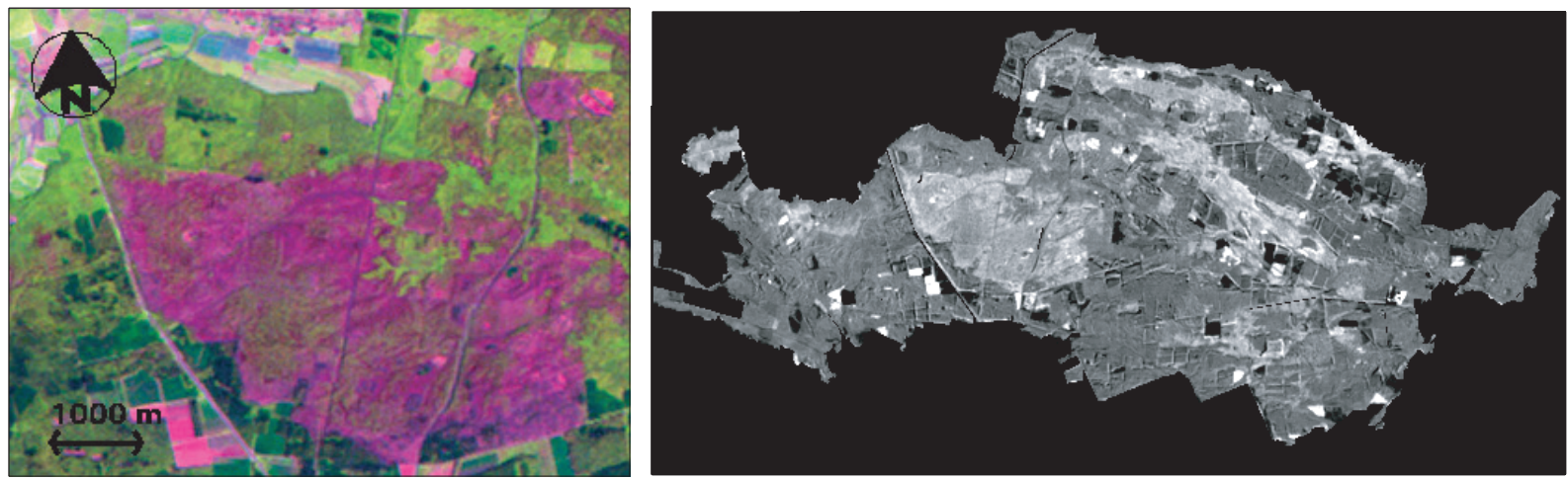

Figure 5. Gipsy moth defoliation mapping using Landsat TM imagery, Haguenau forest, France. Left, extract: colour composite (SWIR channel in red, NIR in green and Red in Blue). Defoliated areas appear in purple. Right, whole forest: difference image between Landsat 1994 and Landsat 1991 (TM 5 - SWIR channel); defoliated areas are in light shades.
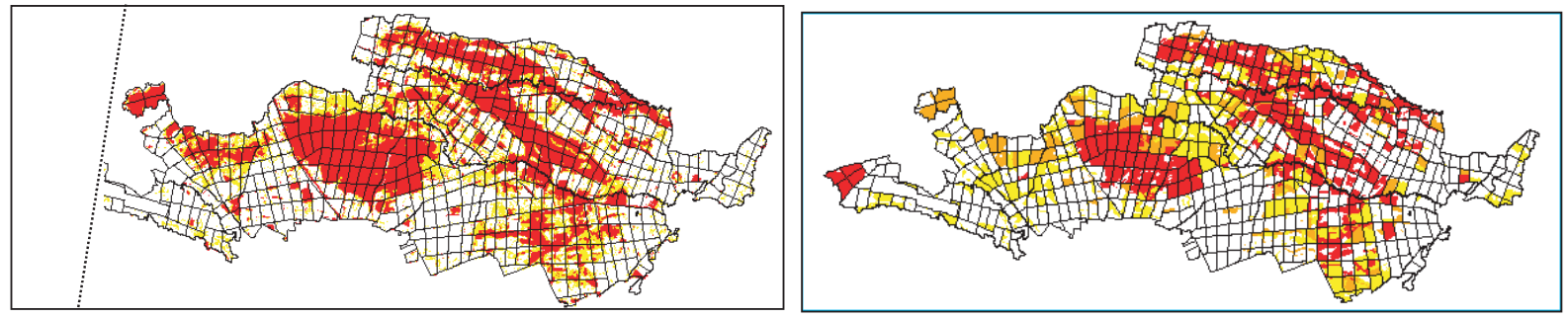

Figure 6. Comparison of gipsy moth defoliation maps derived from Landsat TM imagery (left) and ground observations (right). Haguenau forest, Alsace, France.

\subsection{Monitoring drought effects on vegetation}

The functioning of forest ecosystems results from complex interactions and exchanges between individual trees, undergrowth vegetation, soil and atmosphere, the climatic conditions remaining a major driving force in the evolution and balance of forest ecosystems. The short term impact of climatic extreme events such as severe droughts is a more recent issue, thus explaining why only a few investigations have been carried out on this topic.

This section focuses on water stress and vegetation anomalies as an immediate response to a severe drought. The most innovative results on the drought of 2003 in Europe were obtained on these questions.

\subsubsection{Effects of water stress on vegetation}

Intensive water stress has various ecological and physical impacts on vegetation. Several signs are likely to be detected from remote sensing data. The alteration of chlorophyll and leaf pigments, resulting in leaves turning yellow or brown, influences directly the visible range. The diminution of leaf water content, if strong, may induce an increase of the short wave infrared reflectance. Stomatal closure and reduced transpiration lead to an increase of the thermal infrared response due to the elevation of leaf temperature and reduced latent heat transfer. Water stress can also modify the orientation and the form of leaves and reduce the green LAI; it ultimately can result in an early partial leaves shedding. These manifestations which are closely comparable with an acceleration of leaves senescence concern all wavelengths.

\subsubsection{Vegetation condition}

The Normalised Difference Vegetation Index NDVI is commonly used for monitoring vegetation at continental scale with large swath sensors like VEGETATION, AVHRR, MODIS or MERIS. Using their daily observation frequency, inter-annual variations are easily achievable, giving the opportunity to detect seasonal anomalies between two situations.

Some specific indices have been used to monitor the effects of drought, such as the Vegetation Condition Index VCI proposed by Kogan [61] over north America from AVHRR data time series. The VCI quantifies the vegetation greenness anomalies by comparing the NDVI and its maximal and minimal values observed during the previous years. Drought impact in Brazil was monitored following this method [66]. More recent studies refined the knowledge on the seasonal sensitivity of the relationships between NDVI and meteorologicaldrought indices based on precipitation [53].

With these low resolution sensors, it is difficult to study specific forest types, because the pixel size is often greater than the size of the forest stands. Disaggregation techniques can be applied to low resolution pixels [15]; more detailed information on the forest canopy can then be extracted. In this way, Maselli [71] has shown using a AVHRR/NOAA longterm data series that the NDVI values of small pines and oaks 

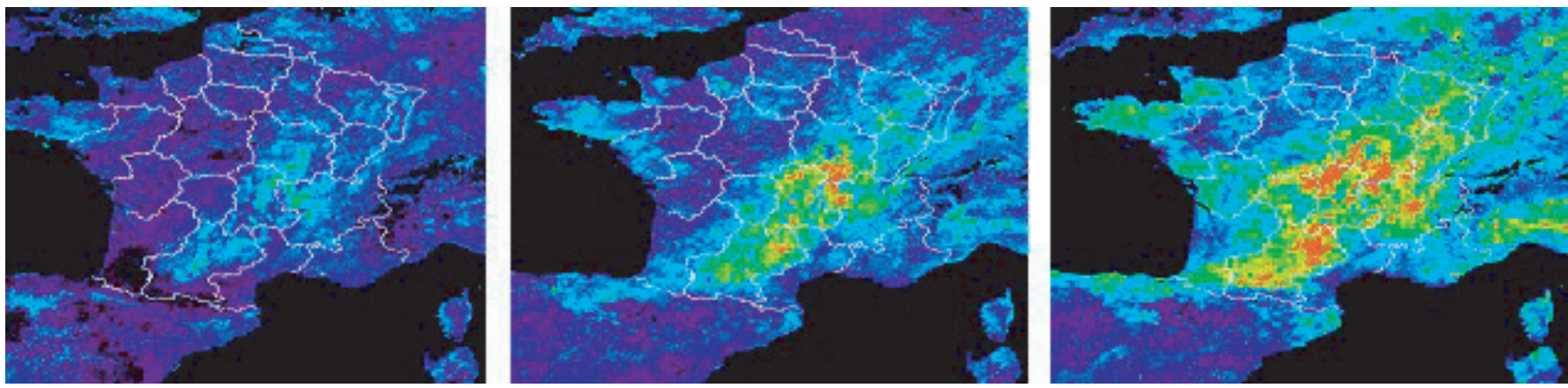

Figure 7. Evolution 2002-2003 of vegetation index (NDVI) from VEGETATION sensor, for months of June, July and August (cf. [45]). Blue colours indicate no major change of vegetation activity between 2002 and 2003. Yellow to red colours indicate a diminution of vegetation activity (less photosynthesis). In August, the effects of drought are particularly visible in southwest to northeast of France. Fires in Var Department are also visible.

forests in Mediterranean region have been decreasing for the last 15 years, as a possible consequence of the diminution of winter rainfall.

The short-term effects of the exceptional 2003 drought on vegetation activity were observed over western Europe using VEGETATION data (Fig. 7). In 2003 an important rain deficit lasted from spring to summer, worsening the impact of an exceptional heat during July and August. The deficit was more severe in eastern and south-eastern France. The effects of drought and heat were visible in forests (foliage yellowing and browning, premature defoliation) and even more so on crops (early drying, early harvesting), and an increased number and a higher intensity of forest fires were also observed. An average NDVI derived from all images acquired during June, July and August 2003 has been computed for each month, and compared with the same periods in 2002. The effects of drought are clearly visible already in June, with an aggravation of the situation in July and even more in August (Fig. 7).

Lobo and Maisongrande [67] have detailed the analysis over Spain and France by comparing the 1999 to 2003 annual profiles of the VEGETATION-derived NDVI. They have observed different responses to drought according to two different phytogeographic and climatic regions, i.e. oceanic and Mediterranean. Negative anomalies of the vegetation index in the summer 2003 were greater for herbaceous vegetation of the oceanic climate region and for deciduous forests. In the Mediterranean region, the NDVI was lower than normal, but the anomalies were less important in absolute value. They also compared the NDVI with the difference between total summer precipitation and total summer potential evapotranspiration, as an estimate of atmospheric water stress. The results indicate that water stress is a major factor structuring the geographic variability of NDVI in the region. The phenological anomalies of NDVI cannot be generalised for all kinds of forests and need some further in-depth analyses. An example is given by Coret et al. [20] from a series of monthly 20-m spatial resolution images, acquired in 2002 and 2003 with the SPOT HRVIR sensor over a $50 \mathrm{~km} \times 50 \mathrm{~km}$ area of south-western France strongly affected by the heat wave. A shortening of the 2003 phenological cycle was observed for the meadows and crops, but the response of the deciduous forests of the studied area was not clear. In the case of the large maritime pine forest of southwestern France, which has not very severely suffered from the 2003 drought, Guyon et al. [43] pointed out that its impact on the seasonal cycle of the VEGETATION-derived signal depends on the nature of undergrowth vegetation. The drought led to an early onset in August of the autumn decline phase of the vegetation index PVI (Perpendicular Vegetation Index). But the effect was not marked over canopies with an evergreen understorey.

Other earth observation data sources have also been investigated to study the effect of 2003 drought on vegetation activity. Multiannual time series acquired over Europe from 1998 to 2003 with the Sea-viewing Wide Field-of-view Sensor (SeaWiFS) and from January 2003 onwards with the Medium Resolution Imaging Spectrometer (MERIS) instrument have been analysed by Gobron et al. [37] to assess the state of health of the vegetation in 2003 and 2004, compared to previous years. By having a similar coverage of the visible and NIR domains (respectively eight and fifteen bands), both sensors allow the computation of comparable vegetation indices. The similar vegetation indices, MGVI (MERIS Global Vegetation Index [38]) and SGVI (SeaWiFS Global Vegetation Index [36]), are good estimators of the Fraction of Absorbed Photosynthetically Active Radiation (FAPAR), an indicator of the state and photosynthetic activity of vegetation. Gobron et al. [37] have shown that the vegetation growth was affected as early as March 2003. An experimental surface wetness indicator derived from the SSM/I (Special Sensor Microwave/Imager) microwave sensor presents spatial patterns of water deficit matching -with a certain time lag- areas with negative FAPAR anomalies. Indeed the water stress was found to precede the vegetation response by up to one month in some places. The situation of spring 2004 was compared with previous years to document the recovery of vegetation. In 2004, the situation has returned to normal, suggesting an absence of observable medium term effect on vegetation at continental scale.

\subsubsection{Soil moisture and vegetation water stress}

Soil moisture is a key parameter for studying the water cycle and for monitoring vegetation activity. It can be studied 
using space sensors operating in passive microwave, with a very low ground resolution (more than $10 \times 10 \mathrm{~km}$ ). SMOS, a space mission in $\mathrm{L}$ band $(1.4 \mathrm{GHz})$ to be launched in 2008 by ESA, will be fully dedicated to soil moisture monitoring as well as ocean salinity (Wigneron et al. 2003). Encouraging results have been achieved with other systems operating at shorter wavelengths (from 5 to $20 \mathrm{GHz}$ ), e.g. SMMR [79] or SMMI (see [37] above).

Besides passive microwave sensors, vegetation water stress can be assessed using remote sensing systems combining simultaneous measurements in the VIS, NIR and TIR wavelengths, as available with NOAA-AVHRR or MSG/SEVIRI sensors. From an operational point of view, NOAA-AVHRR presents several advantages. The main ones are its temporal resolution (four images per day, due to simultaneous operation of 2 satellites) and its good spectral information (visible, near, medium and thermal infrared). The RED and NIR channels (red, 0.58 to $0.68 \mu \mathrm{m}$, and near infrared, 0.72 to $1.10 \mu \mathrm{m}$ ) are used to compute vegetation indices which are correlated with green biomass and photosynthetic activity. The two thermal infrared channels (band 4, 10.3 to $11.3 \mu \mathrm{m}$, and band 5, 11.5 to $12.5 \mu \mathrm{m}$ ) allow the computation of a Surface Temperature corrected for atmospheric and emissivity effects $[39,59,72,100]$. The relation between surface-air temperature and vegetation indices can be useful for estimating water deficit (see for instance [28]). The spatial resolution of NOAA (1.1 km at nadir to $6 \mathrm{~km}$ in oblique view) gives an integration of local variations and provides an average response well adapted to global scale [68]. SEVIRI data from Meteosat Second Generation (MSG) satellite has proved to be useful for monitoring vegetation conditions at high temporal frequency (15-min repeat cycle). Vegetation phenology can be monitored though estimation of the fraction of absorbed photosynthetically active radiation fAPAR and the leaf area index LAI, and water stress is achievable by combining land surface temperature (LST) and soil moisture, albeit at very low resolution [76].

Using the TIR channel of NOAA-AVHRR, the relationship between LST and water balance has been studied at regional scale for temperate forest ecosystems. On coniferous forests, especially in the case of the large maritime pine forest in south western France, LST is a good indicator of water stress as the difference between LST and air temperature may reach about $10{ }^{\circ} \mathrm{C}$ during strong water stress periods, which could be due to the large contribution of the undergrowth vegetation response [28]. Over broadleaved forests, this correlation is not significant as the difference between LST and air temperature is low, whatever the water content of soil, because the aerodynamic roughness of the tree canopy is high and the high tree cover fraction does not allow for a contribution of the understory [11]. In the case of the Mediterranean forests Vidal et al. [101] have shown that the NOAA/AVHRR LST can be successfully used for estimating the seasonal variations of the ratio between the latent heat flux, LE, and the potential latent heat flux, LEp, and for detecting in that way canopy water stress situations.

Finally, numerous references are found in the literature about fire monitoring and fire risk assessment from space. Many of the research activities have developed and tested wa- ter stress indices as a possible tool to anticipate fire risk. Ceccato et al. [16] have shown that water content at leaf level cannot be retrieved from a vegetation stress index. They defined an Equivalent Water Thickness (EWT) which was found to be one of the factors influencing the signal in the SWIR domain. A combination of SWIR and NIR bands is necessary to retrieve EWT at leaf level. Dennison et al. [22] compared the same EWT index to a simple index for measuring regional drought, the Cumulative Water Balance index CWBI which cumulatively sums precipitation and reference evapotranspiration over a period of time. EWT and CBWI were found to be complementary for monitoring live fuel moisture. In another study, Bowyer and Danson [10] have used canopy reflectance models to analyse the canopy reflectance sensitivity to several parameters including EWT, leaf area index (LAI) or fraction of vegetation cover (Fcov). They have shown that if the variations of LAI and Fcov were restricted to a range of values representative of a local site (stand level), the sensitivity of canopy reflectance to EWT in the SWIR domain was very important, more than $65 \%$ of the total sensitivity. In this context, the monitoring of temporal evolution of vegetation water content from space seems possible. However, if the sensitivity of the canopy reflectance to vegetation water content is demonstrated, the radiometric quality of the signal registered by the space borne sensors is still depending on its dynamic range and signal-to-noise ratio, both depending on the impact of atmospheric scattering and bi-directional effects. The question of the radiometric quality of the data is even more crucial if the variation of the vegetation water context itself is narrow, as it has been observed by ground measurements on several species in the Mediterranean basin [99].

\subsubsection{Modelling carbon and water fluxes}

In relation to the increase of greenhouse gases in the atmosphere and the related climate change, major efforts are in progress for a better understanding, monitoring and modelling of the carbon and water cycles as driving forces of global warming. A lot of remote sensing studies are carried out to retrieve LAI and its phenological changes, which are key variables in photosynthesis, transpiration and energy balance. The estimates can be used as input of process-based models or for validating process simulation results. At global scale, the lengthening of the vegetation activity cycle can be monitored using historical long time satellite series [74, 109]. In broadleaved forests, key phenological stages, e.g. budburst, senescence, or length of the seasonal growth, are easily monitored from space at regional scale [27]. In situ measurements tend to confirm the satellite-derived phenological cycle, the latter being only based on detection of seasonal changes in the remote sensing signal (NDVI), without a need for an absolute estimation of LAI. For estimating LAI the situation is more complex. The saturation of the NDVI with high LAI values makes their retrieval difficult. The used algorithms do not often account for the mixing of various vegetation structures in low resolution pixels. This downscaling problem is also critical for the validation of LAI estimates, but also FAPAR or productivity estimates, which more and more become standard 
products available to any user. Wang et al. [102,103] addressed these questions by comparing on several forest sites local continuous ground measurements of LAI, fAPAR and gross primary production (GPP) with their retrieval from medium or low resolution satellites (MODIS, VEGETATION, AHHRR).

Carbon and water fluxes can be estimated using functions of surface transfer between soil, vegetation and atmosphere [14], and simulations of ecosystem functioning processes [75]. Numerous studies address the problem of the coupling of these process models with remote sensing data (see [3]) and their spatial parameterisation. The assimilation of thermal infrared response into the MuSICA model of Ogée et al. [75] is currently being tested over maritime pine stands, and a reduction of errors in the water budget due to the directional and instantaneous measurement of the surface temperature is particularly expected.

Extreme conditions like the 2003 heat and drought event modify the functioning of vegetation: high temperatures, often combined with a severe shortage of water, reduce the vegetation activity (photosynthesis), and as a consequence LAI and the fraction of radiation absorbed by plants (fAPAR) are reduced. This may result in loss of productivity, e.g. for crops. An index of the climatic impact on vegetation production has been developed by Zhang P. et al. [108]: this production index was found to be a good indicator of a drought event as measured by meteorological data.

Model predictions of climate changes and temperature increase tend to indicate that vegetation should be in more favourable conditions in most cases, with increased carbon uptake. However, these schemes are not taking into consideration extreme conditions such as the heat wave of 2003. Using a terrestrial biosphere simulation model to assess continentalscale changes in primary productivity, Ciais et al. [18] have shown that the net ecosystem carbon balance, resulting from the difference between the two opposite carbon fluxes Gross Primary Productivity GPP and ecosystem respiration TER, has been strongly affected in June to September 2003, mainly because of a strong reduction of GPP accompanied by a lesser reduction of TER. The maximum of reduction is observed over France and Germany, and to a lesser extent in Italy and Spain. Forest ecosystems in the temperate region have been more sensitive to drought than Mediterranean ecosystems where the vegetation is already adapted to high temperatures and scarcity of summer rain. These results were based on carbon fluxes modelling using climate and weather data and a land use map derived from high resolution remote sensing data (i.e. Corine Land cover), The simulations reproduced well the GPP and TER anomalies observed over the CarboEurope Eddy Covariance Tower Network. They were also found to be consistent with a fAPAR map derived from space observations (MODIS sensor on board Terra/EOS satellite).

\section{CONCLUSION: WHICH OBSERVATION STRATEGY FOR DROUGHT EFFECTS MONITORING?}

The only existing and operational infrastructure able to monitor forest condition over a very large extent is the pan-
European ground observation network (ICP Forests / EU level 1). If this $16 \times 16 \mathrm{~km}$ network is adapted to an assessment at national or sub-national (regional) scales, it cannot be used at local scale. An access to information at stand scale is necessary for forest management or as an aid to the understanding of spatio-temporal disturbance processes (such as the propagation of bark beetles infestation within and between stands, or the variations between crown condition change of the groundobserved plot and of its surrounding) In such a case, one practical strategy would be to combine high resolution satellite or airborne observations with those of the existing ground system, as a complementary source of information for improving the geospatialisation of interest variables at local scale. For mapping forest damages, the remote sensing data could be used for Interpolating ground observations with geostatistics techniques (i.e. co-kriging).

Airborne and spaceborne sensors represent indeed a unique source of information for monitoring forest response to the 2003 drought at local to regional scale: most of forest canopy anomalies can be easily detected from space, with however a limitation on the true size of the impact, as damage at tree level is still difficult to achieve. An adapted strategy is summarised in Table I. It proposes to combine low and high resolution satellite data with in situ data to carry out vegetation monitoring at local to regional (sub-continental) scales. Low resolution satellites, e.g. with a spatial resolution ranging from $250 \mathrm{~m}$ to several kilometres, are well adapted to a continuous monitoring of global forest condition, with daily to hourly revisit frequency, leading to cloud free compositing every few days. This capability has proved to be extremely useful for monitoring forest seasonal and inter-annual activity. The anomalies of vegetation activity, as seen from a vegetation index or water stress index, could be detected almost in nearreal time with VEGETATION, SeaWiFS, MERIS and SEVIRI data, as early as August 2003. This capability can be extended to following years in order to analyse the forest response to drought in the long term.

At local scale, finer resolution data are more appropriate for deriving parameters at stand to tree level, but only over sites limited in extent. The constellation of the three SPOT satellites may offer a daily revisit over only few selected sites in Western Europe. In the coming years, new systems will be able to offer enhanced possibilities for monitoring forest stands at high revisit frequency and with richer spectral information: the VEN $\mu$ S mission, to be launched in 2009, will be able to capture the same image under the same conditions every two days, with 12 spectral bands at decametric resolution. This approach will be limited to a sampling scheme with the acquisition of images over sample sites where ground measurements are available, e.g. LAI, soil moisture, fraction of vegetation cover, water and carbon fluxes...

Observations from space are able to offer a decisive added value through the synoptic and comprehensive coverage capability, which is critical for better understanding the spatial variability of drought effects on forests. The main drawback is the lack of consistency between the different resolution modes, leading to complex schemes in data fusion or multi-sensor approaches. Due to technical limitations, the finer the resolution, 
Table I. Possible Earth observation strategies for drought effects monitoring.

\begin{tabular}{|c|c|c|}
\hline & Regional monitoring & Local monitoring \\
\hline Geographical extent & Europe & $1-10000 \mathrm{~km}^{2}$, selected sites \\
\hline Spaceborne data source & $\begin{array}{l}\text { Sensors with wide field of view (e.g. VEGETA- } \\
\text { TION, MODIS, MERIS, AVHRR) and very high } \\
\text { revisit frequency }\end{array}$ & $\begin{array}{l}\text { High resolution sensors with high revisit frequency } \\
\text { (e.g. SPOT constellation, VEN } \mu \text { S, Rapid Eye), or low } \\
\text { revisit frequency (Landsat ETM, ASTER...) }\end{array}$ \\
\hline Objectives & $\begin{array}{l}\text { - Monitoring vegetation condition and phenolog- } \\
\text { ical changes: seasonal reflectance and vegeta- } \\
\text { tion indices (NDVI) for year } 2003 \text { and follow- } \\
\text { ing years to be compared with previous years } \\
\text { as reference } \\
\text { - Estimating vegetation surface parameters (LAI, } \\
\text { fAPAR...) and integration (or assimilation) into } \\
\text { physical and physiological processes models : } \\
\text { carbon up-take (GPP, NPP), water fluxes }\end{array}$ & $\begin{array}{l}\text { - Land use and forest inventory applications: land } \\
\text { use and forest mapping, anthropogenic changes } \\
\text { - Detecting and mapping aerial dieback effects and } \\
\text { damages: strong changes of forest conditions or } \\
\text { crown conditions, concentrated damages } \\
\text { - Temporal vegetation profiles (LAI, fcover...) In- } \\
\text { tegration or assimilation into models of vegeta- } \\
\text { tion functioning or of growth at stand level (lim- } \\
\text { ited to sites with intensive ground measurements) }\end{array}$ \\
\hline Advantages & $\begin{array}{l}\text { - Data quickly and easily available, free of } \\
\text { charge } \\
\text { - Global snapshot of Europe } \\
\text { - Temporal profiles of vegetation phenology }\end{array}$ & $\begin{array}{l}\text { - Analysis of forest response at stand level } \\
\text { - Useful for disaggregating low spatial resolution } \\
\text { remote sensing data }\end{array}$ \\
\hline Disadvantages & $\begin{array}{l}\text { Aggregation problem due to the low spatial resolu- } \\
\text { tion, difficulty to analyse small forest stands }\end{array}$ & $\begin{array}{l}\text { No archive as reference } \\
\text { Possibility to monitor only a limited number of sites }\end{array}$ \\
\hline Key issue & \multicolumn{2}{|c|}{$\begin{array}{l}\text { The two approaches are complementary for monitoring the variability of forest response to drought in } \\
\text { time and space } \\
\text { Coupling with existing ground systems is mandatory: research sites with instrumentation, European mon- } \\
\text { itoring networks (ICP level I and level II), Eddy Covariance Tower (Carbon fluxes)... }\end{array}$} \\
\hline
\end{tabular}

the lower the revisit capability: this makes it almost impossible to set up a space observatory over permanent plots with the double capability in resolution and sufficient temporal frequency, e.g. several snapshots per month.

The research efforts carried out so far tend to indicate that, when monitored at sub-continental (regional) to continental scale, vegetation, and specially grasslands and less sensitive Mediterranean vegetation types, has quickly recovered from the 2003 situation. If deciduous forests are found to be severely affected in some areas, it is at this point difficult to know how these vegetation types did recover during 2004, 2005 and further. It should be stressed that 2005 has been another year with water shortage over most of western France and the Iberian Peninsula, thus increasing vegetation stress, whilst it complicates the ability to detect the long term effect of the 2003 drought and heat wave.

New lines of research are expected to contribute applications to the monitoring of vegetation conditions and the detection and assessment of anomalies and damage. Among them:

- the development of digital analysis tools adapted to the assessment of scattered damage on very fine resolution data;

- the development of strategies for a spatial assessment of damages including the use of remote sensing data;

- developments in a number of water stress issues, such as the identification of potential risk areas [12], its interactions with biotic factors [26] and its impact on biodiversity [4];
- developments in water budget modeling and in ecosystem modeling, for their development and their validation, with the use of phenologic information provided by very high temporal frequency sensor, together with multiannual information derived from high and very high resolution data on tree and stand health and vigour at short and long term.

In the medium term (by 2010), the GMES (Global Monitoring for Environment and Security) Programme launched by the European Commission and the European Space Agency is expected to provide data series more suited to a comprehensive monitoring of forest condition at local to regional scales. GMES is based on both space and ground infrastructures. As for land environment, the space infrastructure should be able to deliver cloud free compositing products at decametric resolution every week. This facility is expected to be highly relevant for monitoring forest conditions in Europe. One of the major advances of GMES will be the setting up of operational services dedicated to an effective surveillance of our environment.

\section{REFERENCES}

[1] Anonymous, Remote sensing applications for forest health status assessment. European Union Scheme on the protection of forests against atmospheric pollution, 2nd ed., Office of Publications of European Communities, Luxembourg, 2000, 216 p.

[2] Anonymous, SEMEFOR, Satellite based environmental monitoring of European forests. Project report. European Commission, 
Research Directorate-General Science, Research and development, Environment and climate program 1994-1998, Contract ENV4-CT97-0398, ISBN92-894-0851-0, 2002, 103 p.

[3] Anselmi S., Chiesi M., Giannini M., Manes F., Maselli F., Estimation of Mediterranean forest transpiration and photosynthesis through the use of an ecosystem simulation model driven by remotely sensed data, Glob. Ecol. Biogeogr. 13 (2004) 371-380.

[4] Archaux F., Wolters V., Impact of summer drought on forest biodiversity, Ann. For. Sci. 63 (2006) 643-650.

[5] Bannari A., Morin D., Bonn F., Huete A.R., A review of vegetation indices, Remote Sens. Rev. 13 (1995) 20-95.

[6] Bazire P., Guyon D., Jolly A., Riom J., Lallemand C., Legendre G., Étude par Télédétection spatiale du dépérissement des forêts vosgiennes, in: Colloque Intern. SPOT 1, Utilisation des images, bilan, résultats, Paris, 23-27 novembre 1987, pp. 997-1011.

[7] Bochenek Z., Ciolkosz A., Iracka M., Deterioration of forests in the Sudety Mountains, Poland, detected on satellite images, Environ. Pollut. 98 (1997) 375-379.

[8] Bourgeau-Chavez L.L., Kasischke E.S., Brunzell S., Mudd J.P., Tukman M., Mapping fire scars in global boreal forests using imaging radar data, Int. J. Remote Sens. 23-20 (2002) 4211-4234.

[9] Bowman W.D., The relationship between leaf water status, gas exchange, and spectral reflectance in cotton leaves, Remote Sens, Environ. 30 (1990) 249-255.

[10] Bowyer P., Danson F.M., Sensitivity of spectral reflectance to variation in live fuel moisture content at leaf and canopy level, Remote Sens. Environ. 92 (2004) 297-308.

[11] Bréda N., Duchemin B., Granier A., Lagouarde J.P., Ogée J., Relationships between surface temperature and fluxes: a comparative analysis for temperate deciduous and coniferous forests, in: Proc. International conference, ALPS-CNES, Remote sensing and vegetation productivity, Méribel, 18-22 January 1999, P-15, 4 p.

[12] Bréda N., Huc R., Granier A., Dreyer E., Forest trees and stands under drought: a review of ecophysiological responses, adaptation processes and long-term consequences, Ann. For. Sci. 63 (2006) 623-642.

[13] Brown L., Chen J.M., Leblanc S.G., Cihlar J., A Shortwave Infrared Modification to the Simple Ratio for LAI Retrieval in Boreal Forests: An Image and Model Analysis, Remote Sens. Environ. 71 (2000) 16-25.

[14] Calvet J.-C., Noilhan J., Roujean J.-L., Bessemoulin P., Cabelguenne M., Olioso A., Wigneron J.P., An interactive vegetation SVAT model tested against data from six contrasting sites, Agric. For. Meteorol. 92 (1998) 73-95.

[15] Cardot H., Faivre R., Maisongrande P., Random effects varyingtime regression models: applications in remote sensing, in: Antoch J. (Ed.), Compstat 2004, Physica-Verlag, 2004, pp. 777-784.

[16] Ceccato P., Flasse S., Tarantola S., Jacquemoud S., Grégoire J.M., Detecting vegetation leaf water content using reflectance in the optical domain, Remote Sens. Environ. 77 (2001) 22-33.

[17] CEOS, Committee on Earth observation satellites, http:// www.ceos.org/pdfs/CEOS_brochure_Sep04E.pdf. 2004, 12 p.

[18] Ciais P., Reichstein M., Viovy N., Granier A., Ogée J., Allard V., Aubinet M., Buchmann N., Bernhofer C., Carrara A., Chevallier F., De Noblet N., Friend A.D., Friedlingstein P., Grunwald T., Heinesch B., Keronen P., Knohl A., Krinner G., Loustau D., Manca G., Matteucci G., Miglietta F., Ourcival J.M., Papale D., Pilegaard K., Rambal S., Seufert G., Soussana J.F., Sanz M.J., Schulze E.D., Vesala T., Valentini R., Europe-wide reduction in primary productivity caused by the heat and drought in 2003 , Nature 437-7058 (2005) 529-533.
[19] Ciesla W.M., Dull C.W., Acciavatti R.E., Interpretation of SPOT-1 color composites for mapping defoliation of hardwood forests by gypsy moth, Photogramm. Eng. Remote Sens. 55 (1989) 14651470.

[20] Coret L., Maisongrande P., Boone A., Lobo A., Dedieu G., Gouaux P., Assessing the impacts of the 2003 hot and dry spell with SPOT HRVIR images time series over south-western France, Int. J. Remote Sens. 26 (2005) 2461-2469.

[21] Couteron P., Pelissier R., Nicolini E.A., Paget D., Predicting tropical forest stand structure parameters from Fourier transform of very high-resolution remotely sensed canopy images, J. Appl. Ecol. 42 (2005) 1121-1128.

[22] Dennison P.E., Roberts D.A., Thorgusen S.R., Regelbrugge J.C., Weise D., Lee C., Modeling seasonal changes in live fuel moisture and equivalent water thickness using a cumulative water balance index, Remote Sens. Environ. 88 (2003) 442-452.

[23] Dennison P.E., Roberts D.A., Examining seasonal changes in canopy moisture and vegetation recovery from wildfire using AVIRIS time series data, in: AVIRIS Earth Science and Applications Workshop, March 31-April 2, 2004, Pasadena, California.

[24] Deshayes M., Stach N., Cartographie par télédétection des défoliations des chênes par le bombyx disparate dans le centre-ouest. Rapport final, Convention DERF $N^{\circ}$ 01.40.14/98, 1999, 29 p., 2 cartes hors-texte.

[25] Deshayes M., Stach N., Malphettes J.B., Utilisation des images satellitales pour l'observation des défoliations dues au bombyx disparate en forêt de Haguenau, Les Cahiers du DSF 1 (1998) 87-89.

[26] Desprez-Loustau M.L., Marcais B., Nageleisen L.M., Piou D., Vannini A., Interactive effects of drought and pathogens in forest trees, Ann. For. Sci. 63 (2006) 595-610.

[27] Duchemin B., Goubier J., Courrier G., Monitoring phenological key-stages and cycle duration of temperate deciduous forest ecosystems with NOAA-AVHRR data, Remote Sens. Environ. 67 (1999) 68-82.

[28] Duchemin B., Guyon D., Lagouarde J.P., Potential and limits of NOAA-AVHRR temporal composite data for phenology and water stress monitoring of temperate forest ecosystems, Int. J. Remote Sens. 20 (1999) 895-917.

[29] Durand P., Gelpe J., Lemoine B., Riom J., Timbal J., Le dépérissement du chêne pédonculé dans les Pyrénées Atlantiques, Rev. For. Fr. (Nancy) 35 (1983) 357-368.

[30] Durrieu S., Deshayes M., Méthode de comparaison d'images satellitaires pour la détection des changements en milieu forestier; application aux Monts de Lacaune (Tarn, France), Ann. For. Sci. 51 (1994) 147-161.

[31] Farcy C., Aerial photography and evaluation of Norway spruce decline in the Ardennes, Ann. For. Sci. 46 (1989) 155-171.

[32] French N.H.F., Bourgeau-Chavez L.L., Initial observations of RADARSAT imagery at fire-disturbed sites in interior Alaska, Remote Sens. Environ. 68 (1999) 89-94.

[33] Gao B.-C., NDWI - A Normalized Difference Water Index for Remote Sensing of Vegetation Liquid Water from Space, Remote Sens. Environ. 58 (1996) 257-266.

[34] Gimeno M., San-Miguel-Ayanz J., Evaluation of RADARSAT-1 data for identification of burnt areas in Southern Europe, Remote Sens. Environ. 92 (2004) 370-375.

[35] Gimeno M., San-Miguel-Ayanz J., Schmuck G., Identification of burnt areas in Mediterranean forest environments from ERS-2 SAR time series, Int. J. Remote Sens. 25 (2004) 4873-4888. 
[36] Gobron N., Mélin F., Pinty B., Verstraete M.M., Widlowski J.-L. Bucini G., A Global Vegetation Index for SeaWiFS: Design and Applications, in: Beniston M., Verstraete M.M. (Eds.), Satellite Remote Sensing Data and Climate Model Simulations: Synergies and Limitations, Kluwer Academic Publishers, Dordrecht, 2001.

[37] Gobron N., Pinty B., Melin F., Taberner M., Verstraete M.M., Belward A., Lavergne T., Widlowski J.L., The state of vegetation in Europe following the 2003 drought, Int. J. Remote Sens. 26 (2005) 2013-2020.

[38] Gobron N., Pinty B., Verstraete M.M., Govaerts Y., The MERIS Global Vegetation Index (MGVI): description and preliminary application, Int. J. Remote Sens. 20 (1999) 1917-1927.

[39] Gu X.F., Seguin B., Hanocq J.F., Guinot J.P., Evaluation and comparison of atmospheric correction methods for thermal data measured by ERS1-ATSR, NOAA11-AVHRR, and Landsat5-TM sensors, in: Proceedings of ISPRS 6th International Symposium Physical Measurements and Signatures in Remote Sensing, Val d'Isère, France, 17-21 Janv. 1994, pp. 793-800.

[40] Guyon D., Riom J., Qualité de l'estimation spatiale d'un phénomène évolutif appréhendé par échantillonnage. Exemple de dépérissement des forêts vosgiennes par photographie aérienne, in: Buche P., King D., Lardon S. (Eds.), Séminaire INRA Gestion de l'espace rural et SIG Florac 22-24 octobre 1991, INRA, 1992 pp. 295-305.

[41] Guyon D., Riom J., Kicin J.L., Letouzé F., Courrier G., Applications de la télédétection et des systèmes d'information géographique à l'étude et la gestion des peuplements forestiers dépérissants. Compte-rendu final, novembre 1997, Projet CEE/DGVI (règlement 3528/86) No 92.60.fr.0020. 1997, 75 p.

[42] Guyon D., Berbigier P., Courrier G., Lagouarde J.P., Moreau P., Sensitivity analysis of coniferous forest reflectance with canopy structure and undergrowth characteristics from satellite data and modelling (case study: Landes maritime pine forest), in: CNES (Ed.), 8th International Symposium Mesures Physiques et signatures en télédétection, Aussois, 8-12 January 2001, 387-392.

[43] Guyon D., Cardot H., Hagolle O., Monitoring and mapping the phenology of the maritime pine forest of southwestern France from VEGETATION time-series, in: 2nd International Symposium Recent Advances In Quantitative Remote Sensing, Valencia (Spain), September 25th-29th, 2006.

[44] Guyon J.P., Guyon D., Riom J., Causes et gestion du dépérissement du pin maritime sur le littoral Nord-Atlantique. Rev. For Fr. (Nancy), $\mathrm{N}^{\circ}$ spécial Les dépérissements d'arbres forestiers causes connues et inconnues, 46 (1994), 485-494.

[45] Hagolle O., Lobo A., Maisongrande P., Cabot F., Duchemin B., De Pereyra A., Quality assessment and improvement of temporally composited products of remotely sensed imagery by combination of VEGETATION 1 \& 2 images, Remote Sens. Environ. 94 (2005) $172-186$

[46] Haara A., Nevalainen S., Detection of dead or defoliated spruces using digital aerial data, For. Ecol. Manage. 160 (2002) 97-107.

[47] Harrell P.A., Bourgeau-Chavez L.L., Kasischke E.S., French N.H.F., Christensen N.L. Jr., Sensitivity of ERS-1 and JERS-1 Radar Data to Biomass and Stand Structure in Alaskan Boreal Forest, Remote Sens. Environ. 54 (1995) 247-260

[48] Haussmann T., Lorenz M., Fisher R., Internal Review of ICP Forests, 16th Task Force Meeting of ICP Forests (Gent, Belgium), May 2000, UN/ECE Report, 133 p.

[49] Hildebrandt G., Pilotinventur für eine Europaïsche Wald schadensinventür, in: Proceed. IUFRO Conference, 402/605, Inventoring and Monitoring Endangered Forests, Zürich, 1985, pp. 237-242.
[50] Holmgren P., Thuresson T., Satellite remote sensing for forestry planning - A review, Scand. J. For. Res. 13 (1998) 90-110.

[51] Hunt E.R. Jr., Rock B.N., Detection of changes in leaf water content using near- and middle-infrared reflectances, Remote Sens. Environ. 30 (1989) 43-54.

[52] Jeanjean H., Deshayes M., Synthèse Zones forestières et SPOT4 MIR, in: SPOT4 MIR Synthèse thématique, Centre National d'Études Spatiales, Paris, France, 1998.

[53] Ji L., Peters A.J., Assessing vegetation response to drought in the northern Great Plains using vegetation and drought indices, Remote Sens. Environ. 87 (2003) 85-98.

[54] Jolly A., Estimation par télédétection satellitaire de la récolte annuelle en bois dans la futaie pure de pin maritime du massif des Landes de Gascogne, Apports pour la prévision de la ressource forestière, Thèse de doctorat de l'Université Paul Sabatier de Toulouse, Spécialité: Télédétection spatiale ( $\left.\mathrm{N}^{\circ} 1626\right), 17$ décembre $1993,315 \mathrm{p}$

[55] Jolly A., Guyon D., Riom J., Use of Landsat Thematic Mapper middle infrared data to detect clearcuts in the Landes region, Int. J. Remote Sens. 17 (1996) 3615-3645.

[56] Joria P., Ahearn S., Connor M., A comparison of the SPOT and Landsat Thematic Mapper satellite systems for detecting gypsy moth defoliation in Michigan, Photogramm. Eng. Remote Sens. 57 (1991) 1605-1612.

[57] Kasischke E.S., Bourgeau-Chavez L.L., French N.F., Observations of variations in ERS-1 SAR image intensity associated with forest fires in Alaska, IEEE Trans. Geosci. Remote Sens. 32 (1994) 206 210 .

[58] Kasischke E.S., Melack J.M., Dobson M.C., The Use of Imaging Radars for Ecological Applications - A Review, Remote Sens. Environ. 59 (1997) 141-156.

[59] Kerr Y.H., Lagouarde J.P., Imbernon J., Accurate land surface temperature retrieval from AVHRR data with use of an improved splitwindow algorithm, Remote Sens. Environ. 41 (1992) 197-209.

[60] Kimes B.L., Markham B.L., Tucker C.J., McMurtrey J.E., Temporal Relationships Between Spectral Response and Agronomic Variables of a Corn Canopy, Remote Sens. Environ. 11 (1981) 401-412.

[61] Kogan F.N., Drought of the late 1980s in the US as derived from NOAA polar orbiting satellite data, Bull. Am. Meteorol. Soc. 76 (1995) 655-667.

[62] Kuntz S., Siegert F., Monitoring of deforestation and land use in Indonesia with multitemporal ERS data, Int. J. Remote Sens. 20 (1999) 2835-2853.

[63] Lagouarde J.-P., Ballans F., Moreau P., Guyon D., Coraboeuf D., Experimental study of brightness surface angular variations of maritime pine (Pinus pinaster) stands, Remote Sens. Environ. 72 (2000) 17-34.

[64] Leckie D.G., Jay C., Paradine D., Sturrock R., Preliminary assessment of Phellinus weirii infected (laminated root rot) trees with high resolution CASI imagery, in: Hill D.A., Leckie D.G. (Eds.), Proceedings Automated Interpretation of High Spatial Resolution Digital Imagery For Forestry, International Forum, Victoria, British Columbia, February 10-12, 1998, Natural Resources Canada, Canadian Forest Service, Pacific Forestry Centre, Victoria, British Columbia, 1999, pp. 187-195.

[65] Levesque J., King D.J., Airborne digital camera image semivariance for evaluation of forest structural damage at an acid mine site, Remote Sens. Environ. 68 (1999) 112-124.

[66] Liu W.T., Kogan F.N., Monitoring regional drought using the Vegetation Condition, Int. J. Remote Sens. 17 (1996) 2761-2782. 
[67] Lobo A., Maisongrande P., Stratified analysis of satellite imagery of SW Europe during summer 2003: the differential response of vegetation classes to increased water deficit, Hydrol. Earth Syst. Sci. Discuss. 2 (2005) 2025-2060.

[68] López S., González F., Llop R., Cuevas M., An evaluation of the utility of NOAA-AVHRR images for monitoring forest fire risk in Spain, Int. J. Remote Sens. 12 (1991) 1841-1851.

[69] Luckman A., Baker J., Honzak M., Lucas R., Tropical forest biomass density estimation using JERS-1 SAR: Seasonal variation, confidence limits, and application to image mosaics - active and passive, Remote Sens. Environ. 63 (1997) 126-139.

[70] Mårell A., Leitgeb E., European long-term research for sustainable forestry: experimental and monitoring assets at the ecosystem and landscape level. Part 1: country reports, Technical Report 3, COST Action E25, ECOFOR, Paris, 2005.

[71] Maselli F., Monitoring forest conditions in a protected Mediterranean coastal area by the analysis of multiyear NDVI data, Remote Sens. Environ. 89 (2004) 423-433.

[72] Melia J., Lopez-Baeza E., Caselles V., Segarra D., Sobrino J.A., Gilabert M.A., Moreno J., Coll C. EFEDA Annual Report, EPOCCT90-0030 (LNBE), University of Valencia, 1991.

[73] Miller D.R., Quine C.P., Hadley W., An investigation of the potential of digital photogrammetry to provide measurements of forest characteristics and abiotic damage, For. Ecol. Manage. 135 (2000) 279-288.

[74] Myneni R.B., Keeling C.D., Tucker C.J., Asrar G., Nemani R.R., Increased plant growth in the Northern high latitudes from 19811991, Nature, 386 (1997) 698-702.

[75] Ogée J., Brunet Y., Loustau D., Berbigier P., Delzon S., MuSICA, a $\mathrm{CO}_{2}$, water and energy multi-layer, multi-leaf pine forest model: evaluation from hourly to yearly time scales and sensitivity analysis, Glob. Change Biol. 9 (2003) 697-717.

[76] Pereira J.M.C., Govaerts Y., Potential Fire Applications from MSG/SEVIRI Observations. EUMETSAT Programme Development Department Technical Memorandum No. 07, 2001.

[77] Ranson K.J., Kovacs K., Sun G., Kharuk V.I., Disturbance recognition in the boreal forest using radar and Landsat-7, Can. J. Remote Sens. 29 (2003) 271-285.

[78] Rederstorff D., Dépérissement forestier en Vallée du Rhin Waldschäden im Rheintal. Photointerprétation du dépérissement. Mission aérienne du 9 août 1994, Office National des Forêts - Observatoire écologique de la Harth, Strasbourg, Forstlische Versuch- und Forschunsanstalt Baden-Württemberg, Freiburg-imBreisgau, 1996.

[79] Reichle R.H., Koster R.D., Dong J., Berg A.A., Global soil moisture from satellite observations, lands surface models and ground data: implications for data assimilation, J. Hydrometeo. 5 (2004) 430-442.

[80] Rigina O., Baklanov A., Hagner O., Olsson H., Monitoring of forest damage in the Kola Peninsula, Northern Russia due to smelting industry, Sci. Total Environ. 229 (1999) 147-163.

[81] Rignot E., Salas W.A., Skole D.L., Mapping deforestation and secondary growth in Rondonia, Brazil, using imaging radar and thematic mapper data, Remote Sens. Environ. 59 (1997) 167-179.

[82] Riom J., Le dépérissement du Chêne - Apports de la Télédétection. 1. Forêts des Pyrénées Atlantiques. 2. Forêt du Tronçais (Allier), in: Les Colloques de l'INRA, $\mathrm{N}^{\circ} 32$ : Applications de la Télédétection à l'Agriculture, INRA, Paris, 1984, pp. 117-145.

[83] Riom J., Apport de la télédétection pour l'estimation des dommages aux forêts vosgiennes, Colloque DEFORPA, Nancy, 24-26 février 1988, $32 \mathrm{p}$.
[84] Riom J., Reteau F., Guyon D., Démonstration de l'application de la télédétection par méthode photographique pour l'estimation des dégâts aux forêts. Essai sur le massif forestier vosgien, C.R. de fin de contrat CEE DG VI, APPF/II 5B (VIP F3/81) code INRA 4100A, juin 1987, $120 \mathrm{p}$.

[85] Ripple W.J., Spectral reflectance relationships to leaf water stress, Photogramm, Eng. Remote Sens. 52 (1986) 1669-1775.

[86] Rouse J.W., Haas R.H., Schell J.A., Deering D.W., Monitoring vegetation systems in the Great Plains with ERTS, in: Freden S.C., Becker M. (Eds.), Third earth resources technology satellite-1 symposium, NASA SP-351, Washington, DC, 1974, Vol. 1, pp. 309-317.

[87] Saich P., Rees W.G., Borgeaud M., Detecting pollution damage to forests in the Kola peninsula using the ERS SAR, Remote Sens. Environ. 75 (2001) 22-28.

[88] Schwarz M., Steinmeier C., Holecz F., Stebler O., Wagner H., Detection of windthrow in mountainous regions with different remote sensing data and classification methods, Scand. J. For. Res. 18 (2003) 525-536.

[89] Seguin B., Becker F., Phulpin T., Gu X.F., Guyot G., Kerr Y., King C., Lagouarde J.P., Ottlé C., Stoll P.M., Tabbagh A., Vidal A., A mini satellite project for land surface heat flux estimation from field to regional scale, Remote Sens. Environ. 68 (1999) 357-369.

[90] Siegert F., Kuntz S., Streck C., Bergbauer B., Land use planning and monitoring in Indonesia using ERS-1 RADAR data, in: Proceedings International Conference on Remote Sensing and GIS for Environmental Resources Management - The IndonesianEuropean Experience, Jakarta, Indonesia, 6-8 June 1995.

[91] Skakun R.S., Wulder M.A., Franklin S.E., Sensitivity of the Thematic Mapper enhanced wetness difference index to detect mountain pine beetle red-attack damage, Remote Sens. Environ. 86 (2003) 433-443.

[92] Stach N., L'IFN cartographie les dégâts de la tempête sur le massif aquitain de pin maritime, Géomatique Expert 5 (2000) 15-17.

[93] Stach N., Deshayes M., Durrieu S., Mapping clear-cutting in French forests by satellite remote sensing, in: Olsson H. (Ed.), Proceedings of ForestSat 2005, Borås May 31-June 3 2005, Swedish National Board of Forestry 8a (2005) 118-125.

[94] Stach N., Deshayes M., Le Toan T., Mapping storm damage to forests using optical and radar remote sensing - The case of the December 1999 storms in France, in: Olsson H. (Ed.), Proceedings of ForestSat 2005, Borås May 31-June 3 2005, Swedish National Board of Forestry 8a (2005) 89-93.

[95] Stach N., Deshayes M., Le Toan T., Campillo D., Mathieu G., Évaluation des dégâts de tempête par télédétection satellitaire : aspects méthodologiques et opérationnels, Rapport final, Convention DERF $\mathrm{N}^{\circ}$ 2001-12-132, 2002, 148 p., 2 annexes.

[96] Stone C., Coops N.C., Assessment and monitoring of damage from insects in Australian eucalypt forests and commercial plantations, Aust. J. Entomol. 43 (2004) 283-292.

[97] Tommervik H., Hogda K.A., Solheim L., Monitoring vegetation changes in Pasvik (Norway) and Pechenga in Kola Peninsula (Russia) using multitemporal Landsat MSS/TM data, Remote Sens. Environ. 85 (2003) 370-388.

[98] Tucker C.J., Sellers P.J., Satellite remote sensing of primary production, Int. J. Rem. Sens. 7 (1986) 1395-1416.

[99] Valette J.C., Inflammabilité des espèces forestières méditerranéennes. Conséquences sur la combustibilité des formations forestières, Rev. For. Fr. (Nancy) 42 (1990) 76-92.

[100] Vidal A., Atmospheric and emissivity corrections of land surface temperature measured from satellite using ground measurements or satellite data, Int. J. Rem. Sens. 12 (1991) 2449-2460. 
[101] Vidal A., Pinglo F., Durand H., Devaux-Ros C., Maillet A., Evaluation of a temporal fire risk index in Mediterranean forests from NOAA thermal IR, Remote Sens. Environ. 49 (1994) 296302.

[102] Wang Quan, Tenhunen J., Dinh NguyenQuoc, Reichstein M. Vesala T., Keronen P., Similarities in ground- and satellite-based NDVI time series and their relationship to physiological activity of a Scots pine forest in Finland, Remote Sens. Environ. 93 (2004) 225-237.

[103] Wang Quan, Adiku S., Tenhunen J., Granier A., On the relationship of NDVI with leaf area index in a deciduous forest site, Remote Sens. Environ. 94 (2005) 244-255.

[104] Wigneron J.P., Calvet J.C., Pellarin T., Van De Griend A., Berger M., Chanzy A., Ferrazzoli P., Retrieving near surface soil moisture from microwave radiometric observations: current status and future plans, Remote Sens. Environ. 85 (2003) 489-506.

[105] Yanasse C.d.C.F., Sant'Anna S.J.S., Frery A.C., Renno C.D., Soares J.V., Luckman A.J., Exploratory study of the relationship between tropical forest regeneration stages and SIR-C L and C data, Remote Sens. Environ. 59 (1997) 180-190.

[106] Yu G.R., Miwa T., Nakayama K., Matsuoka N., Kon H., A proposal for universal formulas for estimating leaf water status of herbaceous and woody plants based on spectral reflectance properties, Plant Soil 227 (2000) 47-58.

[107] Zarco-Tejada P.J., Miller J.R., Harron J., Hu B., Noland T.L., Goel N., Sampson P.H., Mohammed G.H., Hyperspectral remote sensing of forest condition: estimating chlorophyll content in tolerant hardwoods, For. Sci. 49 (2003) 381-391.

[108] Zhang P., Anderson B., Barlow M., Tan B., Myneni R.B., Climate-related vegetation characteristics derived from Moderate Resolution Imaging Spectroradiometer (MODIS) leaf area index and normalized difference vegetation index, J. Geophys. Res. Atmos. 109 (2004).

[109] Zhang X.Y., Friedl M.A., Schaaf C.B., Strahler A.H., Climate controls on vegetation phenological patterns in northern mid- and high latitudes inferred from MODIS data, Glob. Change Biol. 10 (2004) $1133-1145$. 